\title{
Using Joint Scaling Methods to Study Ideology and Representation: Evidence from Latin America
}

\author{
Sebastián M. Saiegh \\ Department of Political Science, University of California, San Diego, La Jolla, CA 92093 \\ e-mail: ssaiegh@ucsd.edu (corresponding author) \\ Edited by R. Michael Alvarez
}

\begin{abstract}
In this article, I use joint scaling methods and similar items from three large-scale surveys to place voters, parties, and politicians from different Latin American countries on a common ideological space. The findings reveal that ideology is a significant determinant of vote choice in Latin America. They also suggest that the success of leftist leaders at the polls reflects the views of the voters sustaining their victories. The location of parties and leaders reveals that three distinctive clusters exist: one located at the left of the political spectrum, another at the center, and a third on the right. The results also indicate that legislators in Brazil, Mexico, and Peru tend to be more "leftists" than their voters. The ideological drift, however, is not significant enough to substantiate the view that a disconnect between voters and politicians lies behind the success of leftist presidents in these countries. These findings highlight the importance of using a commonspace scale to compare disparate populations and call into question a number of recent studies by scholars of Latin American politics who fail to adequately address this important issue.
\end{abstract}

\section{Introduction}

At the turn of the twenty-first century, the Left experienced an extraordinary revival in Latin America. In country after country, the so-called "new Left" managed to defeat the Center and the Right in free and fair elections (Smith 2012). In fact, by 2009 nearly two-thirds of Latin Americans lived under some form of leftist national government (Levitsky and Roberts 2011). Many scholars, however, argue that leftist leaders' success at the polls does not reflect the views of Latin American citizens. For example, Seligson (2007) finds that Latin American citizens' ideological self-placement on the left-right scale is actually skewed to the right. Arnold and Samuels (2011) and Booth and Bayer Richard (2015) use survey data to document a weak connection between mass public opinion and the region's leftist electoral victories. Likewise, Remmer (2012) claims that although electoral support for the left in several Latin American countries increased in the early 2000s, the mean citizen placement on the left-right scale in 2007 was slightly more rightist than in 1996.

These findings are quite paradoxical, suggesting not only that ideology may not be a significant determinant of vote choice in Latin America, but also that elected officials display an appreciable ideological drift from the public. I contend that the alleged ideological disconnect between voters and politicians in Latin America is mainly an artifact of measurement error. These previous studies have primarily relied on perceptual data to compare disparate populations. Such a reliance presents three main problems: (1) individual-level respondent bias; (2) biases in scale perception across countries; and (3) disjoint groups facing disjoint sets of choices (i.e., politicians and voters surveyed in different ways). I address these issues by constructing more accurate measures of the policy preferences of both citizens and politicians in Latin America. Specifically, I use joint scaling

\footnotetext{
Authors' note: Supplementary Materials for this article are available on the Political Analysis Web site. Replication files are available on the Political Analysis Dataverse at http://dx.doi.org/10.7910/DVN/29342. The research for this article was conducted while the author was a visiting research scholar at the Inter-American Development Bank's Research Department (RES).
} 
methods and similar items from three large-scale surveys to place voters, parties, and politicians from different Latin American countries in a common ideological space.

I proceed in three stages. First, I rely on the 2010 Latinobarómetro to estimate the ideological location of 11,245 respondents from eighteen Latin American countries. The survey contains rating scales to evaluate several prominent political leaders who are well known throughout the region (e.g., Fidel Castro, Hugo Chávez, and Barack Obama). As such, it is possible to employ these questions as the "glue" to jointly scale respondents from all countries. Second, I analyze data from eight countries included in the most recent wave of the Universidad de Salamanca's Parliamentary Elites of Latin America (PELA) survey, which focuses on elected officials. I examine responses to questions where legislators were presented with the task of locating themselves and a number of relevant political actors on a ten-point ideological scale. Some common stimuli-consisting of prominent Latin American politicians - are used in all eight countries. I thus rely on these data to estimate the location of parties and politicians from different countries in a common ideological space. Third, I combine some of the PELA surveys with Module 3 of the Comparative Study of Electoral Systems (CSESs) to jointly place voters and elected officials in four Latin American countries (Brazil, Chile, Mexico, and Peru) on a common ideological scale. These surveys focus on two different sets of respondents: voters in the case of CSES and legislators in the PELA survey. But both surveys ask respondents to locate themselves and a common set of relevant political actors on a ten-point ideological scale. Therefore, these common questions serve as bridges to connect the policy preferences of voters within each country to the preferences of the legislators who represent them.

The evidence indicates that Latin Americans' voting behavior does not lack for policy or ideological content. In particular, the results suggest that: (1) ideology is a significant determinant of vote choice; and (2) the success of leftist leaders at the polls reflects the views of their supporters. The analysis of elite ideology reveals that three distinctive clusters exist: one located at the left of the political spectrum, another one at the center, and a third one to its right. Finally, the results show that irrespective of their ideological location, legislators in Brazil, Mexico, and Peru tend to be more "leftists" than their voters. Yet, this representation gap is not significant enough to claim that the electoral success of Latin America's left is rooted in a disconnect between mass public opinion and their leaders.

These findings underscore the drawbacks of using unscaled ideological self-placements to infer the location of respondents. They also demonstrate how joint scaling methods can be used to estimate comparable ideological positions of voters and political parties across countries. In this respect, this article is closely related to recent analyses of Europe's common ideological space by König, Marbach, and Osnabŕ'ugge (2013); Lo, Proksch, and Gschwend (2014); and Bakker et al. (2014). ${ }^{1}$

The analysis also has important implications for our understanding of who votes for the left in Latin America. The existing literature has struggled to explain why alienated, or even right-wing, voters would support left-wing candidates (cf. Castañeda and Navia 2006; Debs and Helmke 2010; Murillo, Oliveros, and Vaishnav 2010; Levitsky and Roberts 2011; Remmer 2012; Booth and Bayer Richard 2015). In addition, the findings in this article call into question a number of recent studies by scholars of Latin American politics who fail to adequately address the issue of cross-context comparability (Colomer 2005; Seligson 2007; Arnold and Samuels 2011; Remmer 2012; Wiesehomeier and Doyle 2012; Lupu 2013; Zechmeister and Corral 2013; Booth and Bayer Richard 2015).

The remainder of this article is organized as follows. In Section 1, I discuss Latin America's alleged representation gap. In Section 2, I review the main problems associated with self-reported measures of ideology. In Section 3, I introduce the data used in this study, while in Section 4 I present my main empirical findings. A final section concludes.

\footnotetext{
${ }^{1}$ In addition, this study nicely aligns with Jessee (2010), Shor and Rogowski (2010), Shor (2011), Tausanovitch and Warshaw (2013), Battista, Peress, and Richman (2013), Jessee and Malhotra (2013), Malhotra and Jessee (2014), and Abrajano (2015), who use common items and joint scaling techniques to examine issues of representation in the United States.
} 


\section{The Quality of Representation}

The relationship between public opinion and policymaking is central to normative and empirical theories of democracy. Citizens are considered to be well represented when governments implement policies that are congruent with the public's preferences. In contrast, a "representation gap" exists when the preferences and opinions of the represented are given little consideration by their representatives (Powell 2004; Shapiro 2011). In addition, when policy responsiveness is weak or biased relative to majority opinion, the consequence is ideological incongruence (Lax and Phillips 2012).

Following the pathbreaking study by Miller and Stokes (1963), a gargantuan literature in political science uses survey data to examine the quality of representation. In the United States, most studies measure quality as the congruence between constituents' preferences and the behavior of their representatives (see Shapiro [2011] for a recent survey of this literature). The comparative research primarily directs its attention to the ideological proximity of parties and citizens (Huber and Powell 1994; McDonald, Mendes, and Budge 2004; Whitefield 2006; Powell 2004, 2009; Golder and Stramski 2010). Both strands of the literature, however, face several methodological problems. For example, most empirical research on constituent representation uses correlational measures. Yet, as demonstrated by Achen $(1977,1978)$, correlations between the policy stances taken by legislators and by constituents fail to establish if their viewpoints are actually proximate to one another. With regard to the comparative politics literature, McDonald, Mendes, and Budge (2004) demonstrate that studies using mass surveys to establish citizens' ideological locations suffer from systematic respondent-level bias. I discuss some of these problems in greater detail below.

\subsection{A Representation Gap in Latin America?}

The early 2000s witnessed an unprecedented increase in the electoral victories of left-of-center presidential candidates in Latin America. Traditionally, the Latin American Left drew on socialism - and even Marxism - for ideological inspiration. By the 1990s, however, leftist candidates became more moderate and ambiguous as their parties watered down or abandoned their preexisting platforms (Stokes 2001). Left-of-center candidates also coexist with equally moderate right-wing candidates, as well as myriad populist movements in the region. Although populists often appeal to an ill-defined pueblo, or "the people," against an established elite, these appeals can seldom be defined in programmatic or ideological terms (Levitsky and Roberts 2011). So, for example, populist politicians such as Peru's Ollanta Humala may not be easily located along the conventional left-right ideological spectrum.

The persistence of populism and the fact that both left- and right-wing candidates pursue diverse agendas suggest that parties' standpoints may not necessarily be defined in programmatic or ideological terms. In fact, much of the extant literature has discussed the classification of leftist governments (Castañeda and Navia 2006; Cleary 2006). And, the controversy over the proper labels for various administrations continues to influence and shape the debate on the Latin American left (Levitsky and Roberts 2011).

Less attention has been paid in the literature to the political orientation of the forces sustaining these administrations. Some studies, however, use public opinion data to identify the relationship between the beliefs and attitudes of Latin American citizens and the electoral success of leftist candidates in the region (Colomer 2005; Seligson 2007; Lupu 2009; Arnold and Samuels 2011; Remmer 2012; Wiesehomeier and Doyle 2012; Zechmeister and Corral 2013; Booth and Bayer Richard 2015). Drawing on self-reported measures of ideology, these studies find that most Latin American voters have a clear and coherent understanding of the ideological meaning of left and right. Their findings also indicate that the median Latin American voter is slightly to the right of center. As such, some of these studies conclude that the success of leftist leaders at the polls does not reflect the ideological orientation of Latin America's citizens along the left-right ideological spectrum (Seligson 2007; Arnold and Samuels 2012). For example, using data from the 2010 AmericasBarometer survey, Booth and Bayer Richard (2015) conclude that governments and the ideological position of citizens are not always in synchrony. In particular, they report that even though Venezuela and Nicaragua have presidents from leftist parties, the mean ideology of 
Venezuelans is slightly on the right side of the scale and that Nicaraguans are not significantly different from the regional mean (Booth and Bayer Richard 2015).

Other studies find that ideology is associated with vote choice in Latin America (Lupu 2009; Remmer 2012). Nonetheless, they present inconsistent and/or mixed results. For example, the findings in Lupu (2009) indicate that respondents' ideology affects their vote choices in Bolivia, Mexico, Peru, Uruguay, and Venezuela, but not in Chile and Brazil. Remmer (2012), in turn, finds that a correlation between self-placement on the left-right scale and support for leftist presidents exists in Bolivia, Brazil, Chile, Uruguay, and Venezuela, but not in Argentina (where rightist sentiments bolster approval of President Kirchner).

Overall, the existing empirical evidence is quite paradoxical. It suggests: (1) that ideology may not be a significant determinant of vote choice in Latin America; and (2) the existence of a considerable representation gap between elected officials and the public. In other words, the conventional wisdom implies that either Latin Americans' voting behavior is somewhat devoid of policy or ideological content, or elected officials in the region are not fully responsive to their constituents. As I demonstrate below, however, this perceived representation gap is mainly an artifact of measurement error due to problems of interpersonal comparability, or differential item functioning (DIF).

\section{Self-Reported Ideology: Measurement Problems}

The aforementioned studies rely on perceptual data to place voters, parties, and politicians from different countries in a common ideological space. Such a reliance presents three main problems: (1) individual-level respondent bias; (2) biases in scale perception across countries; and (3) disjoint groups facing disjoint sets of choices (i.e., politicians and voters surveyed in different ways). In this section, I describe these problems in more detail, and discuss how valid measures of ideology from disparate populations can be estimated.

\subsection{Differential Item Functioning}

Issue scales are frequently used to measure ideology in public opinion. These surveys often ask people to place themselves and prominent politicians on a scale with labeled endpoints such as "liberal" and "conservative" or "left" and "right." A well-known difficulty associated with this approach is the problem of systematic respondent-level bias, or DIF (Aldrich and McKelvey 1977; Palfrey and Poole 1987; Alvarez and Nagler 2004). ${ }^{2}$

Survey respondents within a given country may display systematic perceptual biases when placing stimuli on a common scale for a number of reasons. First, predetermined scales force respondents to cluster on only seven or ten points. As such, survey-based estimates of respondents' preferences tend to be too coarse (Kam 2001). Second, the scale may have different meanings to different people. Namely, respondents may be anchoring their responses according to their own interpretation of the endpoints. ${ }^{3}$ Third, and associated with the ambiguity of the endpoints, is the problem that respondents may interpret the intervals on the scale differently. For example, an extreme leftist may see less difference between a center-left and center-right politician than a moderate would. Finally, as Aldrich and McKelvey (1977) note, given the forced categorization, respondents may place the stimuli, as well as themselves, more frequently in the "prominent" categories (one, three, five, seven, and nine).

Figure 1 provides a good illustration of some of these biases. It shows the perceived location of the main Mexican parties on a left-right ideological scale (where 1 is left and 10 is right) obtained

\footnotetext{
${ }^{2}$ The use of DIF to refer to systematic respondent-level bias originated in the educational testing literature: a test question is said to have DIF if equally able individuals have unequal probabilities of answering the question correctly (cf. King et al. 2004).

${ }^{3}$ Moreover, the fact that respondents are asked to locate themselves on the scale may exacerbate this tendency (Wilcox, Sigelman, and Cook 1989). For example, a respondent who perceives himself/herself as a true "leftist" is likely to interpret the endpoints of the left-right scale in order to accommodate his/her own ideal point, thus pushing his/her perceptions of the candidates farther to the right than a "less committed leftist" would.
} 


\section{Perceived Location of Main Parties in Mexico}

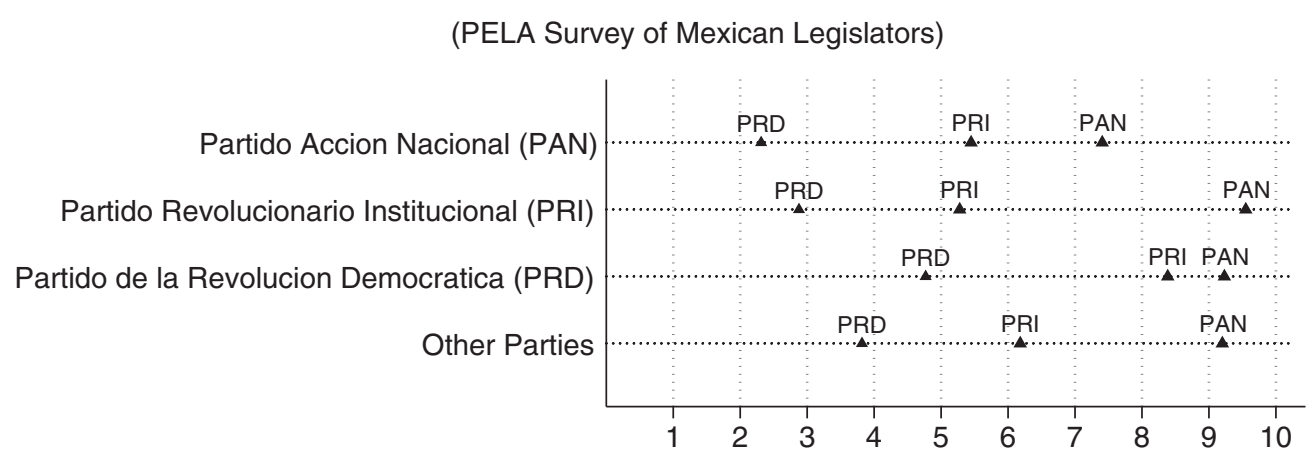

Fig. 1 Example of systematic perceptual biases: Mexico (2010).

from the responses of ninety-eight national legislators included in the 2010 wave of the PELA survey.

I classified the respondents by their political affiliation, and calculated the average score given to different parties by the legislators in each group. ${ }^{4}$ So, for instance, the legislators who belong to Mexico's Party of the National Revolution (Partido de la Revolución Nacional, PRD) place the Institutional Revolutionary Party (Partido Revolucionario Institucional, PRI) and the National Action Party (Partido Acción Nacional, PAN) very close to the right end of the scale (at 8.38 and 9.23, respectively).

As Fig. 1 clearly demonstrates, the respondents exhibit systematic perceptual biases. They all place the parties in the same order (from left to right): the PRD, the PRI, and the PAN. The location of each of these parties, however, varies significantly according to the respondent's partisan affiliation. According to the PRI legislators, the PAN is located at the rightmost end of the scale (at 9.55). Yet, the PAN legislators place their party closer to the center of the scale (at 7.4). Indeed, as Fig. 1 shows, all legislators tend to place their own parties closer to the center and the other parties closer to the extremes.

The consequences of DIF are as well understood as its sources. In essence, the difficulty is that if one uses the raw data to make inferences, the conclusions can be seriously misleading. For example, it is possible that complete agreement exists in the perceptions of the stimuli, but due to different interpretations of the scale, one might interpret this as little or no agreement. It is still possible, however, to obtain reliable estimates of respondents' ideological preferences from survey data by using the appropriate scaling techniques. ${ }^{5}$ One of the most satisfactory approaches is the AldrichMcKelvey (henceforth A-M) scaling procedure (King et al. 2004; Armstrong et al. 2014a; Hare et al. 2014). Therefore, in my analysis, I rely on the A-M solution to the DIF problem in survey responses.

\subsection{Cross-Country Comparisons}

Biases in scale perception arise because labels such as "liberal" and "conservative" or "left" versus "right" often depend on context, in both time and space. Therefore, the problem of cross-context comparability can be compounded when survey respondents in different geographical locations are

\footnotetext{
${ }^{4}$ I classified under $O$ thers legislators who belong to the Mexican Green Party (Verdes), Labor Party (Partido del Trabajo, PT), New Alliance (Nueva Alianza), and Convergence (Convergencia).

${ }^{5}$ King et al. (2004) suggest the use of anchoring vignettes as a method to evaluate and improve the information revealed by surveys. These vignettes are descriptions of hypothetical people or situations that survey researchers can use to correct otherwise interpersonally incomparable survey responses. Ideally one would like to use such vignettes to enhance interpersonal comparability when measuring the preferences of key political actors. The use of the vignettes, however, must be implemented at the design stage. Therefore, it may not be possible to rely on them when secondary data are used.
} 
asked to place themselves and various political actors on an abstract left-right scale. For example, in the United States, Conservative means one thing in Texas and something different in Massachusetts (Shor 2011). Likewise, the PELA survey reveals that many respondents in Chile place the political party National Renewal (Renovación Nacional, RN) at eight on a ten-point leftright scale and a number of respondents in Argentina also place the Peronist Party (Partido Justicialista, PJ) at an eight on the same scale; yet most observers would agree that these two parties do not occupy the same ideological position on the left-right scale (Coppedge 2010; Murillo, Oliveros, and Vaishnav 2010).

Producing cross-national measures of party positions is analogous to the problem of estimating comparable preferences across political institutions or over time (Shor 2011). A conventional way to address this issue is to use bridge actors; for example, members of Congress who serve multiple terms, or who migrate from the House to the Senate. Using European political groups to identify the location of parties in different European countries is another case in point (König, Marbach, and Osnabŕ'ugge 2013; Lo et al. 2014). An alternative approach is to treat questions that are asked in the same form to respondents in different countries as bridges to create a common spatial map (Shor 2011). The respondents' answers to common questions can be then used to place different stimuli (i.e., parties or prominent politicians) on the same latent scale, thus facilitating cross-context comparisons.

\subsection{Disjoint Samples}

Applying scaling techniques such as Aldrich-McKelvey requires some sort of bridging information. This limitation usually prevents one from directly comparing policy preferences between disjoint groups responding to disjoint sets of choices. For instance, studies seeking to establish if legislators faithfully represent their constituents' views often lack the necessary data to conduct meaningful tests. In the case of citizens, their ideology is usually recovered from voting decisions or selfreported measures from survey data; yet legislators' policy preferences are often estimated using observable roll call voting decisions.

Recent research seeks to measure the preferences of voters and politicians on a common scale. Gerber and Lewis (2004) recover legislators' ideology using roll call votes and obtain comparable estimates of voter preferences from data on statewide ballot measures in Los Angeles County, California. Likewise, Bafumi and Herron (2010) combine legislators' voting records from the 109th-110th Congresses with public opinion data to obtain comparable measures of ideology. Legislators, however, take positions in a context that is fundamentally different from the context of public opinion polling. Therefore, one should avoid placing their behavior on the same scale as public opinion (Lewis and Tausanovitch 2013).

A good solution to the disjoint samples problem is to use surveys of voters and politicians containing a common set of questions. This is the approach used by Shor and Rogowski (2010), who use common items from Project Vote Smart's National Political Awareness Test and the National Annenberg Election Study to generate comparable measures of voter and candidate ideology. Tausanovitch and Warshaw (2013) and Battista, Peress, and Richman (2013) use a similar strategy to examine policy representation in Congress, state legislatures, and cities in the United States. This approach holds an important virtue because, unlike measures of ideology based on legislative behavior, survey responses are not contaminated by the effects of legislative or party institutions, including party discipline, agenda-setting, log-rolls, and the like. ${ }^{6}$ In a similar vein, Malhotra and Jessee (2014) use an original survey asking respondents about their positions on cases decided by Supreme Court to locate citizens and justices on the same ideological scale.

The A-M method can be used to recover the ideological location of both respondents and stimuli. In the case of the former, each respondent's rating can be transformed into an ideology

\footnotetext{
${ }^{6}$ In some of these studies, the respondents cannot be individually identified, as the surveys are anonymous. While this places a restriction on matching the responses with other data sources, it ensures that responses are sincere. As Kam (2001) notes, there seem to be little incentive for respondents to misrepresent their preferences in an anonymous survey.
} 
score by applying his/her perceptual distortion parameters to that score. Therefore, as long as both legislators and voters answer some of the same questions (including a self-placement one), one can use the Aldrich-McKelvey estimation technique to obtain measures of ideology that are both valid and comparable across these two groups within each country.

\section{Data and Estimation}

\subsection{Latinobarómero}

I first use the Latinobarómetro, an annual public opinion survey, to scale respondents from different Latin American countries in a common ideological space. The survey is produced by Latinobarómetro Corporation, a non-profit non-governmental organization based in Santiago, Chile. Various local opinion-research companies conducted the 2010 survey in eighteen countries. This wave of the survey involved 20,204 face-to-face interviews conducted between September and October 2010. In each country, the sample size of 1000-1200 respondents is representative of $100 \%$ of its population, with a margin of error of approximately $3 \%$. As such, the survey is representative of the region's more than 500 million inhabitants. ${ }^{7}$

The survey instrument is identical in all countries. To bridge respondents across countries, I rely on a battery of questions asking them to evaluate some of the region's presidents as well as overseas leaders using an eleven-point scale (where 0 means "very bad" and 10 is "very good"). Few respondents rate all stimuli. Still, respondents do not limit their evaluations to politicians from their own country. For example, only 3557 respondents rated Uruguayan president José Mujica, but this figure almost triples the country's sample size (1200). On the other hand, some leaders, such as Barack Obama, Fidel Castro, and Hugo Chávez, were rated by more than $60 \%$ of the respondents. I thus consider fourteen stimuli for which at least $17 \%$ of the respondents provided a rating. ${ }^{8}$

\subsection{Parliamentary Elites of Latin America}

To place parties as well as prominent politicians from different Latin American countries in a common space, I use the PELA survey. Established in 1994 by a group of researchers at the Universidad de Salamanca (Spain), the PELA surveys contain information regarding party membership, attitudes, opinions, beliefs, values, and policy preferences of legislators in eighteen Latin American countries. ${ }^{9}$

Over the past two decades, Latin American legislators have been asked to place themselves as well as political parties and prominent politicians on a left-right ideological scale. In particular, the following prompt has been consistently used: "When we talk about politics, the expressions left and right are usually used. Where would you place $<$ yourself $>$ on a scale where 1 is left and 10 is right?" Questions containing political stimuli, such as a country's main political parties or its leading politicians, are phrased in the same way. Until the most recent wave of the PELA surveys, however, legislators were only asked to place parties/leaders from their respective country. Therefore, despite their common design, those PELA surveys are still limited instruments to foster systematic cross-national comparisons.

Fortunately, in the 2010-11 wave, legislators were also asked to place a number of regional leaders on the left-right ideological scale. Only eight countries, however, were included in this most recent wave. A total of 823 legislators participated in these surveys, all of them drawn from samples mirroring the relative importance of their political parties in the different legislatures. ${ }^{10}$ There are at least seven stimuli that were rated by more than $82 \%$ of respondents. Therefore, I use legislators'

\footnotetext{
${ }^{7}$ For more details, go to www.latinobarometro.org.

${ }^{8}$ See the online Supplementary Materials for a stimuli list as well as their response rates.

${ }^{9}$ For a more detailed description of the PELA project, go to http://americo.usal.es/oir/elites/.

${ }^{10}$ The countries covered by these surveys are Argentina (with 70 respondents), Bolivia (97), Brazil (129), Chile (86), Colombia (91), Mexico (98), Peru in 2010 (80), Peru in 2011 (93), and Uruguay (79).
} 
responses to these "bridge" questions (i.e., placement of regional leaders) to estimate the locations of parties and prominent Latin American politicians in a common ideological space. ${ }^{11}$

\subsection{Comparative Study of Electoral Systems}

One final goal of this article is to develop common space estimates for elected officials and a sample of voters. Unfortunately, the Latinobarómetro and PELA surveys do not contain identical survey items in this respect. The former asks respondents to express how much they like/dislike a set of leaders (preferential data), while the latter asks them to place the stimuli (as well as themselves) on a left-right ideological scale (perceptual data). Nevertheless, it is possible to bridge legislators and voters using common items found in the PELA survey and Module 3 of the CSESs. The CSES is a collaborative program of research among election study teams from around the world. The core questionnaire of CSES Module 3 focuses on voters' perceptions and assessments of the variety and quality of political choices in an election. The module was implemented using face-to-face interviews administered to a nationally representative sample of voters in Brazil (with 2000 respondents), Chile (1200), Mexico (2400), Peru (1570), and Uruguay (968). ${ }^{12}$

Although the PELA and CSES surveys are not identical, they contain similar items. Specifically, they ask respondents to place themselves as well as political parties and prominent politicians from their own country on a left-right ideological scale. ${ }^{13}$ Moreover, the two sets of surveys were conducted simultaneously. Note that the voters are not placing the elites as stimuli. Instead, both sets of respondents locate themselves and a common set of relevant political actors (parties, presidential candidates) on a ten-point ideological scale. ${ }^{14}$ Therefore, one can merge these two surveys into a common data set by treating politicians as if they were voters to get them in the same space within each country. ${ }^{15}$

\subsection{Estimation}

The basic A-M model assumes that given a set of respondents $I=\{1, \ldots, n\}$ and a set of stimuli $J=\{1, \ldots, m\}$, the perceived location of stimulus $j$ by individual $i$, denoted by $z_{i j}$, is given by

$$
z_{i j}=\alpha_{i}+\beta_{i} Z_{j}+e_{i j}
$$

where $Z_{j}$ is the true location of $j, \alpha$ is an intercept capturing a respondent's systematic bias in the reported placements, $\beta$ captures any expansions or contractions of the reported placements on the scale, and $e_{i j}$ is a random variable that has zero expectation, positive variance that is independent of $i$ and $j$ (homoscedastic), and zero covariance across the is and js (Aldrich and McKelvey 1977; Hare et al. 2014). ${ }^{16}$ Given the $z_{i j}$ matrix of reported positions, the A-M scaling procedure recovers the location of the stimuli using singular value decomposition (SVD), and subsequently estimates the individual transformation parameters $\alpha$ and $\beta$. Finally, these distortion parameters are used to calculate the respondents' ideological location.

\footnotetext{
${ }^{11}$ I exclude from the analysis respondents that rate less than three stimuli. Detailed information regarding the seven stimuli that provide the bridging along with their response rates can be found in the online Supplementary Materials.

${ }^{12}$ For more details, see www.cses.org.

${ }^{13}$ The CSES question reads: "In politics people sometimes talk of left and right. Where would you place [YOURSELF/ STIMULUS] on a scale from 0 to 10 where 0 means the left and 10 means the right?" The PELA scale's endpoints are 1 and 10; therefore, for comparability, I recoded respondents' answers from a 0 to 1 in the CSES survey.

${ }^{14}$ For example, in Brazil, both CSES and PELA respondents were asked to place themselves and 2010 presidential candidates Dilma Rousseff and José Serra, as well as to locate the position of the Workers' Party (PT), the Brazilian Democratic Movement Party (Partido do Movimento Democrtico Brasileiro), the Democrats (Democratas, DEM), the Brazilian Labour Party (Partido Trabalhista Brasileiro), the Brazilian Social Democracy Party (Partido da Social Democracia Brasileira), and the Democratic Labour Party (Partido Democrtico Trabalhista).

${ }^{15}$ I provide information regarding "bridging" questions and the timing of the interviews in the two surveys in the Supplementary Materials published online.

${ }^{16}$ The assumption of homoscedastic errors is clearly unrealistic. Palfrey and Poole (1987), however, demonstrate that the A-M procedure recovers the locations of the stimuli very well, even if errors are heteroskedastic over them.
} 
To jointly scale parties and politicians from different countries in a common ideological space, I rely on the Bayesian implementation of the Aldrich-McKelvey method used in Hare et al. (2014). ${ }^{17}$ The Bayesian A-M model assumes that the perceived location of stimulus $j$ by individual $i$ follows a distribution:

$$
\begin{aligned}
z_{i j} & \sim N\left(\mu_{i j}, \tau_{i j}\right) . \\
\mu_{i j} & =\alpha_{i}+\beta_{i} Z_{j} . \\
\tau_{i j} & =\tau_{i} \tau_{j} .
\end{aligned}
$$

Following Hare et al. (2004), I employ noninformative uniform priors for the individual distortion parameters $\left(\alpha_{i} \sim U(-100,100)\right.$ and $\left.\beta_{i} \sim U(-100,100)\right)$. I also use standard normal priors for the estimates of the stimuli positions (e.g., $Z_{j} \sim N(0,1)$ ). Finally, I employ diffuse inverse Gamma priors for both the stimuli and respondent-specific precision terms ( $\tau_{j}$ and $\tau_{i}$, respectively). As Hare et al. (2014) note, estimating these unique stimuli and respondent error variances allows for heteroskedastic error. ${ }^{18}$

The Bayesian Aldrich-McKelvey (BAM) technique provides better estimates of the stimuli (parties and politicians) than the respondents (voters/legislators). Therefore, I use it for my second exercise (comparing parties and politicians across countries). My first exercise requires that I successfully deal with missing responses and preferential data. Poole (1998) generalizes the A-M solution using an alternating least squares (ALS) technique instead of SVD to handle missing data. In addition, his procedure can be applied to perceptual as well as preference data. Therefore, I rely on his technique for the first exercise (voter ideology). For my third exercise, where I use perceptual data to compare the ideology of legislators and voters in a given country, I use the original Aldrich and McKelvey implementation (1977). ${ }^{19}$

\section{Empirical Findings}

The results in this section demonstrate that correct scaling of ideological locations can enhance our understanding of political representation in Latin America. First, I analyze the ideological position of voters. Second, I examine the location of parties and politicians from eight different countries in a common space. Finally, I connect the policy preferences of voters and legislators in four countries. $^{20}$

\subsection{Voters' Ideological Locations}

Using common items to bridge across countries, I apply Poole's (1998) "blackbox" method to the preferential data from the 2010 Latinobarómetro survey described above and estimate a onedimensional solution for the respondents' left-right position. I exclude from the analysis respondents that failed to rate more than three stimuli. Using this criterion, I can recover the ideological location of more than half of the respondents in the sample $(55.6 \%$, or 11,245 respondents). The measures of ideology are defined only up to an affine transformation of the true space (Armstrong et al. 2014a). Therefore, in order to identify the rotation of the estimated positions, I correlate the recovered scores with the respondents' self-reported ideology scores, where higher scores indicate

\footnotetext{
${ }^{17}$ The R code, as well as the BUGS and Just Another Gibbs Sampler (JAGS) scripts necessary to conduct the analysis, were obtained from http://www.voteview.com/BAM.asp. For a more detailed description of the methodology, see Armstrong et al. (2014b) and Hare et al. (2014).

${ }^{18}$ In order to introduce exchangeability between the $\tau_{i}$ parameters, inverse Gamma hyperpriors are also placed on the shape and scale parameters of the inverse Gamma priors for these terms (Hare et al. 2014). Specifically, $\tau_{j} \sim \operatorname{Gamma}(0.1,0.1), \tau_{i} \sim \operatorname{Gamma}(v, \omega), v \sim \operatorname{Gamma}(0.1,0.1)$, and $\omega \sim \operatorname{Gamma}(0.1,0.1)$.

${ }^{19}$ The basicspace package on CRAN contains the software to implement the A-M method (with the aldmck function) as well as the Blackbox scaling procedure (with the blackbox function). For more details, see Poole et al. (2013).

${ }^{20}$ The results can be reproduced using the replication materials in Saiegh (2015).
} 


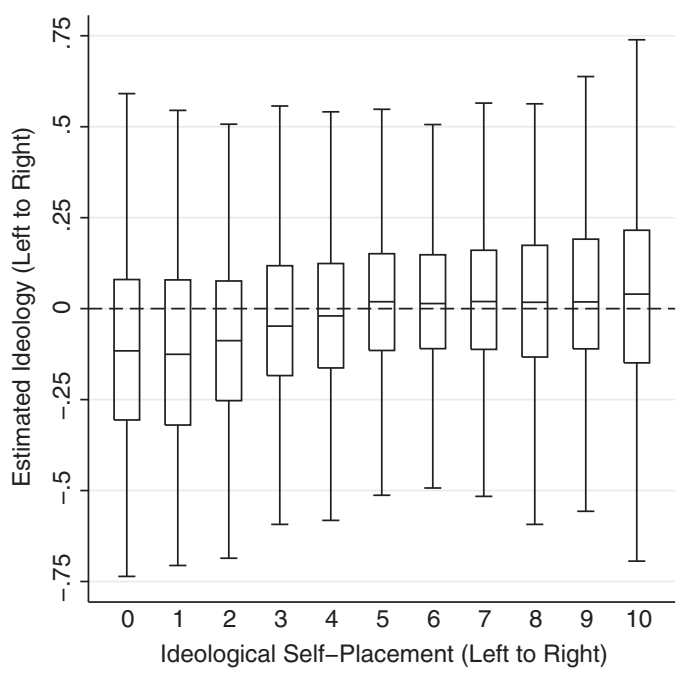

Fig. 2 Respondents' ideological self-placement and estimated ideology.

placements on the right end of the scale. The correlation is positive, suggesting that as the recovered scores increase, the respondents tend to be on the right. ${ }^{21}$

Figure 2 displays a boxplot with the distribution of the respondents' recovered ideological locations (vertical axis) according to their self-reported, unscaled, ideological location (horizontal axis). For example, the first box from the left corresponds to the estimated ideology of the respondents who place themselves on the left end of the scale (i.e., they located themselves at 0 ). ${ }^{22}$ Therefore, the graph includes eleven boxes, with each one extending from approximately the first to third quartiles.

The estimates from Fig. 2 suggest that preferential data can be effectively used to infer the placement of survey respondents in an ideological space. The black band inside each box marks the location of the second quartile (the median) of the recovered estimates of ideology. As Fig. 2 indicates, the black band is located below 0 in the vertical axis in the boxes corresponding to the respondents who identify as "leftists" (i.e., those who use answers of $\{0,1,2,3,4\}$ on the eleven-point scale). Likewise, the black band is located above 0 in the boxes corresponding to the respondents who identify as being on the right of the political spectrum (i.e., those who use answers of $\{5,6,7,8,9,10\}$ on the eleven-point scale) ${ }^{23}$

Although the recovered estimates and the self-placement data are correlated, it is possible that the respondents' assessments do not reflect information about left-right ideology. For example, by rating Obama, Castro, and Chávez, the respondents' assessments may reflect their impressions of US policy toward Latin America rather than meaningful measures of left-right political ideology. Another concern is that, because the bridging technique rests on the respondents' ability to rate leaders of several countries, the resulting sub sample may not be representative of the larger population. Using data from the 2010 AmericasBarometer survey, Zechmeister and Corral (2013) show that the percentage of respondents who are able and willing to place on the left-right scale varies considerably across Latin American countries. Moreover, their results indicate that ideological selfplacements are systematically linked to respondents' education, political interest, and political sophistication as well as their stances on political, economic, and social issues. Their findings raise the possibility of nonrandom selection in the Latinobarómetro survey as well.

\footnotetext{
${ }^{21}$ The Latinobarómetro question reads: 'In politics, people normally speak of 'left' and 'right.' On a scale where 0 is left and 10 is right, where would you place yourself?"

${ }^{22}$ I exclude from the comparison respondents who do not provide a self-reported score on the 0-10 scale (i.e., those who answered "None," "Don't Know," or "No Answer").

${ }^{23}$ Strictly speaking, 0 represents the (unweighted) mean of the estimated stimuli. Therefore, it might not necessarily indicate the location of the ideological "center."
} 
A conventional way to address both issues is to estimate the probability of being in the restricted sample and then use this information to correct the estimates for the outcome of interest; in this case, it is the relationship between issues and left-right placements (Heckman 1979). I consider two sets of models: one focusing on the respondents' self-placement on the left-right scale, and the other where I concentrate on the respondents' ability to rate more than three leaders. Therefore, the dependent variable in the selection equation is either: (1) a dummy variable, which takes a value of 1 for those who responded to the ideology question and 0 for those who did not respond (combining those who offered no response at all and those who stated they do not know); or (2) a dummy variable, which takes a value of 1 for those who rated three of more stimuli and 0 for those who failed to do it. In predicting these responses, and following Zechmeister and Corral (2013), I include measures of the respondent's level of education, political interest, and political knowledge. I also control for the respondent's age, gender, and socioeconomic level. ${ }^{24}$ The results indicate that for the self-reported measures of ideology, the residuals for the two stages are uncorrelated. But, in the case of the respondents' ability to rate more than three leaders, the results suggest that there is negative selection or truncation effects in these data. Given the rotation of the estimated ideological positions, this finding implies that relative to respondents with average characteristics drawn at random from the Latinobarómetro sample, those who can rate leaders of several countries tend to be more leftist.

The second stage examines the correlation between issues and ideology. The dependent variable is either: (1) the respondent's placement on the 0 (left) to 10 (right) scale, recoded here as $z$-scores; or (2) my recovered estimates of ideology. To assess the substantive determinants of the respondents' ideological positions, I also follow Zechmeister and Corral (2013) and include measures capturing four issue dimensions that are relevant to Latin American politics: gay rights, relationship with the United States, regional integration, and state-market relations. The results indicate that my recovered estimates do not merely reflect the respondent's views regarding US policy toward Latin America, but rather constitute meaningful measures of left-right political ideology. ${ }^{25} \mathrm{~A}$ second noteworthy finding is that, while consistent with the results from the "self-placement" model, the coefficient estimates in the model using my recovered estimates of ideology as the dependent variable are much more precise (i.e., the point estimates' confidence intervals are much smaller). ${ }^{26}$

The latter finding should not be too surprising, given the measurement error associated with selfreported measures of ideology. As Fig. 2 indicates, the degree of dispersion in the estimated ideological locations for each of the categories of the self-reported ideology scale is quite significant. In fact, a considerable number of respondents place themselves at the endpoints ( 0 and 10$)$, when their actual positions in the underling left-right dimension are at the center. In addition, respondents place themselves more frequently in a few "prominent" categories (five, six, and seven). If the spacing between the different parts of each of the boxes was minimal, then the problem of interpersonal comparability or DIF could be dismissed. Yet the evidence indicates that if one uses the unscaled ideological self-placement data to make inferences about the location of Latin American voters, the conclusions can be seriously misleading. As such, these findings cast doubts over the conclusions of studies that do not account for DIF (Colomer 2005; Seligson 2007; Arnold and Samuels 2011; Remmer 2012; Wiesehomeier and Doyle 2012).

I am now in a position to answer the following questions using the corrected measures of voters' policy preferences: Are partisan attachments devoid of ideological content in Latin American

\footnotetext{
${ }^{24} \mathrm{I}$ include country-fixed effects in all the models. To address heteroskedasticity, I employ Huber-White robust standard errors (clustered at the country level). The dependent variables in both models are mean-centered, thus ensuring that the assumption of normality of the error terms is adequately addressed. In addition, the standard errors of the estimates must be adjusted for the selection process. In the results presented here, all standard errors have already been corrected. For more details about the specification of these models, please see the online Supplementary Materials.

${ }^{25}$ After controlling for attitudes toward the United States, respondents who believe that the government should have a more active role in the economy and who support Latin America's regional integration tend to place themselves on the left of the ideological continuum. In addition, those who favor same-sex marriage are more likely to identify themselves with the left. In contrast, respondents with pro-market views lean to the right.

${ }^{26}$ For example, the role of government has no statistically significant impact on self-placement. But when my measure of ideology is considered, its effect is significant (and in the expected direction).
} 
countries? Is it true that Latin Americans tend to support "leftist" governments? The Latinobarómetro survey includes the following question: "If elections were held this Sunday, which party would you vote for?" Most of these countries are multi-party democracies. To simplify the analysis, I focus on two types of parties: those included in the government coalition and those in the opposition. Fortunately, every political party in each of the eighteen Latin American countries has been classified using this criterion in the survey. Therefore, the relationship between partisanship and ideology can be established using the recovered estimates and the respondents' vote intentions. ${ }^{27}$

With a response rate of $49.6 \%$ (5578 out of the 11,245 scaled respondents), the vote choice question also raises concerns regarding nonrandom selection. I rely again on a Heckman selection model, and adopt the same specifications as the ones discussed above to address this issue. In this case, to produce the selection variable, I estimate a probit model where the dependent variable takes a value of 1 for those who named a specific party as their vote choice and 0 for those who answered "Do Not Know" or "Will Not Vote." Next, I use this information to correct the estimates of the correlation between issues and estimated ideology. Finally, I estimate a model using the respondents' ideology as the dependent variable and the selection instrument and country-specific constants as my independent variables. I partition the sample into two groups of respondents (based on their vote choice), and estimate a separate model for each group by ordinary least squares regression. I thus generate two sets of selection-corrected parameters, one for respondents who support the government and the other for those in the opposition. The coefficients of the country-specific constants indicate the ideological location of each country's representative government/opposition voter. $^{28}$

The left panel of Fig. 3 displays the ideological location of the "typical" government (black circle) and opposition (white circle) respondent in each country (arranged ideologically from left to right). Dots are point estimates of the country-specific constants, and the spikes depict $95 \%$ confidence intervals. The solid vertical line indicates the location of the typical voter in the sample. The dashed (dotted) vertical line indicates the location of the representative government (opposition) voter in the sample. ${ }^{29}$

Left-wing governments are likely to have left-wing supporters, and right-wing governments are likely to have right-wing supporters. In addition, in only a few countries, the typical government supporter is located to the right of the typical government voter in the sample. These "rightist" voters expressed their support for the parties of presidents Sebastian Piñera (Chile), Juan Manuel Santos (Colombia), Porfirio Lobo (Honduras), and Alan García (Peru). In contrast, in eight countries, the representative government voter is located to the left of the representative government supporter in the sample. And all these countries were led by prominent members of the so-called Latin American "pink tide": Cristina Fernández de Kirchner (Argentina), Evo Morales (Bolivia), Mauricio Funes (El Salvador), Álvaro Colom (Guatemala), Daniel Ortega (Nicaragua), Fernando Lugo (Paraguay), José Mujica (Uruguay), and Hugo Chávez (Venezuela). With regard to the opposition, the data suggest that its typical voter is located to the right of the representative government voter in Latin America.

The right panel of Fig. 3 plots the difference between the estimates based on recovered ideology measures and analogous estimates created with the raw (self-reported) ideology scores. Dots are the differences in the point estimates, and the spikes depict $95 \%$ confidence intervals. Deviations from zero can be interpreted as the perceptual bias of each country's typical voter. Negative values indicate that the respondent places himself/herself too low on the scale, while positive values indicate the opposite. The results highlight how DIF systematically biases survey responses. For example, the typical government voter in Argentina and Guatemala perceives himself/herself as more moderate than he/she really is. In most countries led by "pink-tide" leaders (Nicaragua,

\footnotetext{
${ }^{27}$ For details about how the parties are classified, see the 2010 survey codebook at www.latinobarometro.org.

${ }^{28}$ The online Supplementary Materials provide additional information regarding the specification of these models.

${ }^{29}$ For all the comparisons, I focus on relative distances between the voters. As mentioned above, although it would seem natural to consider " 0 " to be the center, the scales are only relatively identified. And 0 does not necessarily correspond to the location of the ideological "center."
} 
Recovered Estimates

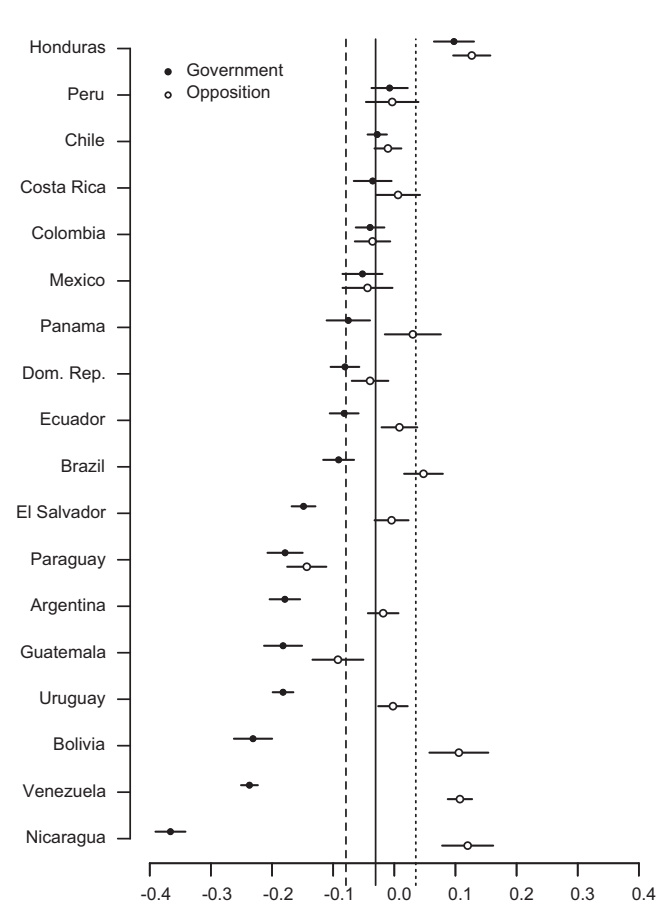

Perceptual Bias

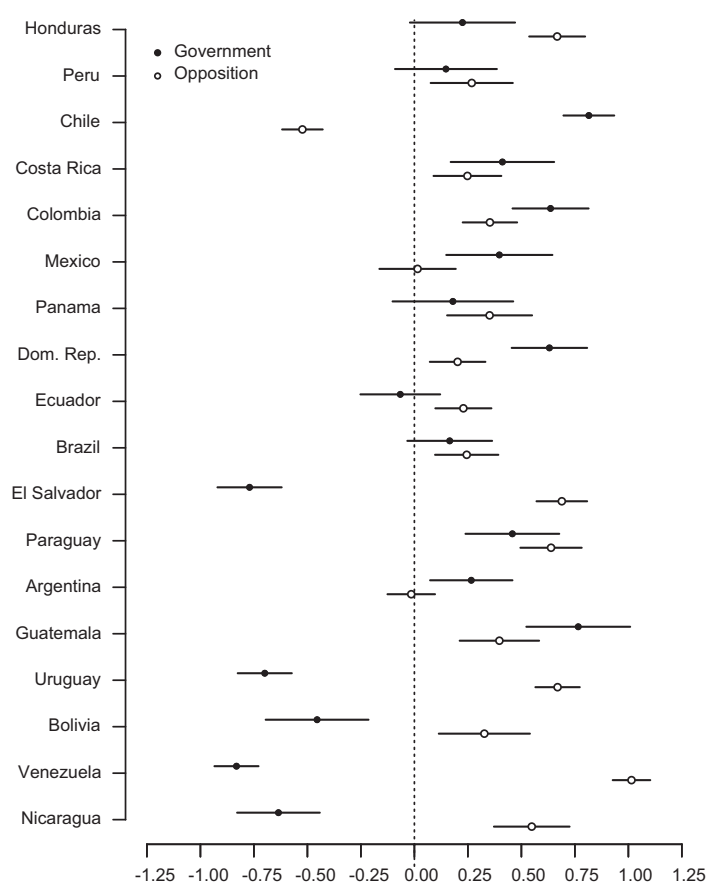

Fig. 3 Ideological location of representative voters.

Venezuela, Bolivia, Uruguay, and El Salvador), however, government voters tend to overstate their ideological extremism. This is also the case in most of the countries governed by right-wing presidents (Chile, Colombia, and Mexico). In addition, with few exceptions (Mexico and Argentina), opposition voters in Latin America also tend to report relatively extreme positions in their selfplacements. As such, the evidence presented in the right panel of Fig. 3 suggests that failing to correct for DIF would overstate the true extent of polarization in the region.

My recovered estimates of ideology can also be compared with previous conclusions in the literature (see Lupu 2009; Remmer 2012). Figure 4 displays the relationship between a respondent's ideology and the probability of voting for the government's party. Two non-parametric fit lines, obtained through locally weighted scatterplot smoothing (lowess), are presented. The solid line corresponds to the self-reported ideology, while the dotted line indicates the recovered estimates of ideology. For comparison purposes, both measures are expressed as $z$-scores. Negative values correspond to left-of-center ideological orientations, and positive ones to right-of-center positions.

The evidence indicates that for the Latin American region as a whole, the non-parametric fit line for the corrected measure is steeper than the one for the self-reported ideology. Locally weighted smoothing is based on an iterative process based on many model fits. Therefore, there are no confidence intervals associated with the fit lines. Nonetheless, it is possible to establish whether the difference in slope is statistically distinguishable from zero in a couple of ways. The first one is to model the relationship between a respondent's ideology and the probability of voting for the government's party using linear, quadratic, and polynomial regressions (Royston and Altman 1994). The results suggest that the difference in the fit lines' slopes is statistically significant. Another approach is to compare the distributions of the two non-parametric estimates using a Harrell-Davis estimator in conjunction with a percentile bootstrap (Wilcox et al. 2014). The results indicate that there are significant differences between the two distributions at the $.05, .25, .75$, and .95 quantiles (see the online Supplementary Materials for more details).

The superiority of the recovered estimates is particularly evident in the cases of Argentina, Bolivia, Brazil, Ecuador, Nicaragua, Venezuela, and the Dominican Republic. For example, 

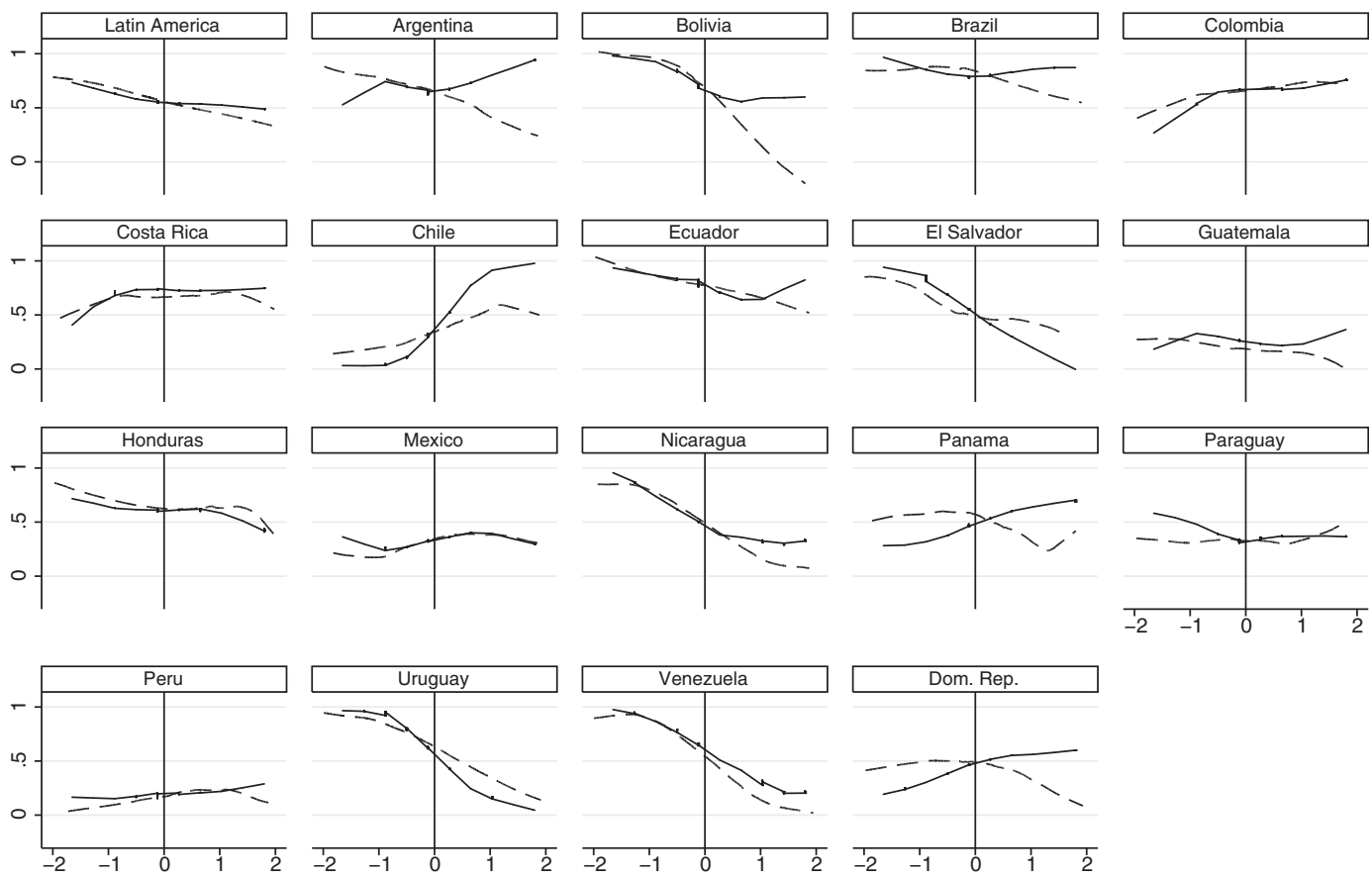

— Self-Reported - - . Recovered Estimates

Fig. 4 Expected probability of voting for government (lowess fit).

based on the self-reported ideology measure, one would conclude with Remmer (2012) that rightwing voters are more likely to support President Kirchner than left-wing voters. Yet, as Fig. 4 indicates, this conclusion would be an artifact of measurement error. Likewise, the correlation between ideology and vote choice among right-wing voters in the other countries is captured more accurately by the recovered estimates than by the self-reported measure of ideology. More generally, the evidence in Fig. 4 highlights the main pitfall associated with using perceptual data to compare disparate populations.

Finally, it is worth noting that the estimates presented in the left panel of Fig. 3 allow one to make meaningful comparisons between voters across different countries. For instance, the typical voter of Mexico's ruling party in 2010 - the National Action Party (PAN) - is located to the right of the representative voter of Argentina's Peronist Party (PJ). And the representative voter of Nicaragua's Sandinista National Liberation Front (Frente Sandinista de Liberacin Nacional) is located to the left of the typical supporter of Brazil's Workers' Party (Partido dos Trabalhadores, PT).

One can learn even more from these comparisons by looking at the whole distribution of voters rather than just the typical voter. Weyland (2011) draws a distinction between radical versus moderate left-wing governments in Latin America. The former include the Chávez and Morales administrations in Venezuela and Bolivia, respectively, while the latter refer to Brazil's Lula and Chile's Concertación. The evidence indicates that supporters of radical-left leaders are quite different than supporters of moderate-left ones. Consistent with Weyland's characterization, government supporters in Bolivia and Venezuela are more radical in their ideological views than followers of moderate-left leaders. As such, the examination of voter preferences further substantiates the claim that there is hardly a disconnect between the mass public and their leaders in these four countries.

\subsection{The Latin American Ideological Space}

In the 2010-11 PELA surveys, legislators from eight Latin American countries were asked to place themselves as well as political parties, prominent politicians, and regional leaders on a left-right 


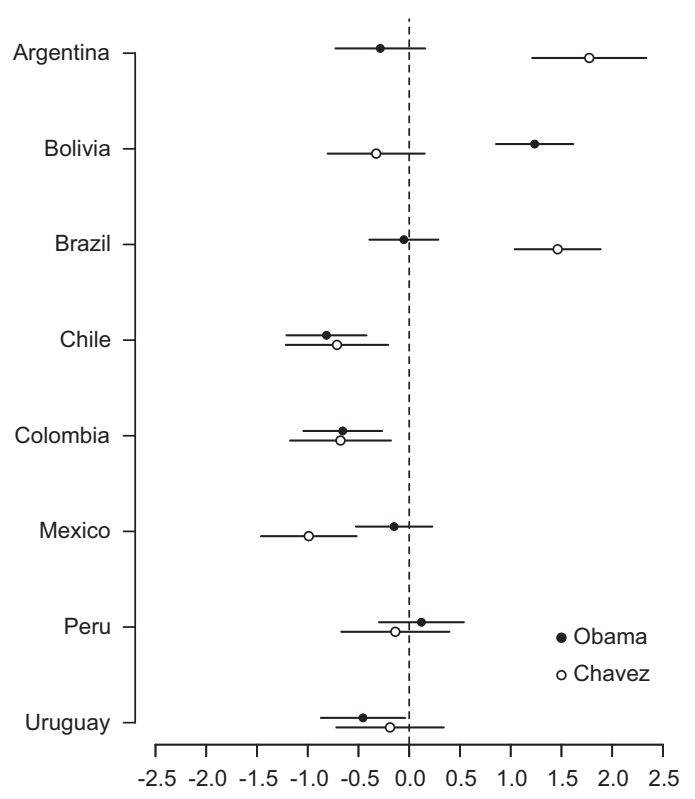

Fig. 5 Perceptual bias of PELA respondents.

ideological scale. Using these data and joint scaling methods, one can reliably compare the positions of parties and prominent politicians from different countries with far more confidence than previous studies. ${ }^{30}$

Of course, it is important to document whether a problem of cross-country comparability actually exists in order to justify the necessity of using a common-space scale. To measure biases in scale perception by legislators of different countries, I consider the difference between their mean ideological placement of Barack Obama and Hugo Chávez (arguably the most well-known leaders, used as bridge items) and the sample average (excluding the legislators' own country) in the raw (unscaled) data. These differences are presented in Fig. 5. Dots represent the mean of the difference of the two groups for Obama (black marker) and Chávez (white marker), and the spikes depict 95\% confidence intervals. Deviations from zero can be interpreted as the perceptual bias of each country's typical legislator. Positive values indicate that the respondent is placing stimuli too far rightward, and negative values indicate that the respondent is placing the stimuli too far leftward. ${ }^{31}$

It is clear from Fig. 5 that the location of Obama and Chávez varies significantly across countries. Compared with the sample average, Hugo Chávez is seen as being far more moderate by the typical Argentine and Brazilian legislator. In contrast, the typical Bolivian legislator considers Obama to be much more rightist than the sample average indicates. And, in two of the countries (Chile and Colombia), the typical legislator rates both Obama and Chávez as too leftist. Therefore, the evidence presented in Fig. 5 indicates that we should not rely on the raw (unscaled) data to compare these disparate populations.

Figure 6 presents the point estimates and 95\% credible intervals for the stimuli (arranged ideologically from left to right) obtained using the Bayesian A-M scaling procedure. ${ }^{32}$ These results have a high degree of face validity: the ideological space closely resembles existing classifications

\footnotetext{
${ }^{30}$ For example, Coppedge (2010) restricts his attention to political parties and classifies them as left, center-left, center, center-right, and right. Murillo, Oliveros, and Vaishnav (2010) and Blanco and Grier (2013) use a similar scale to characterize the ideology of Latin American presidential candidates and elected presidents, respectively. Wiesehomeier and Benoit (2009) use expert surveys to jointly identify the ideologies of Latin American presidential candidates as well as political parties. These authors, however, do not correct for DIF.

${ }^{31}$ To calculate these differences, I used an independent sample $T$-test assuming unequal variances.

${ }^{32}$ MCMC estimation of the model was conducted using JAGS and the R package rjags (Plummer 2003, 2013). Identification was obtained by constraining Hugo Chávez to lie between -1.1 and -0.9 and Alvaro Uribe to lie between 0.9 and 1.1. I discarded the first 10,000 iterations as a burn-in period, and I summarized the results of 2500
} 


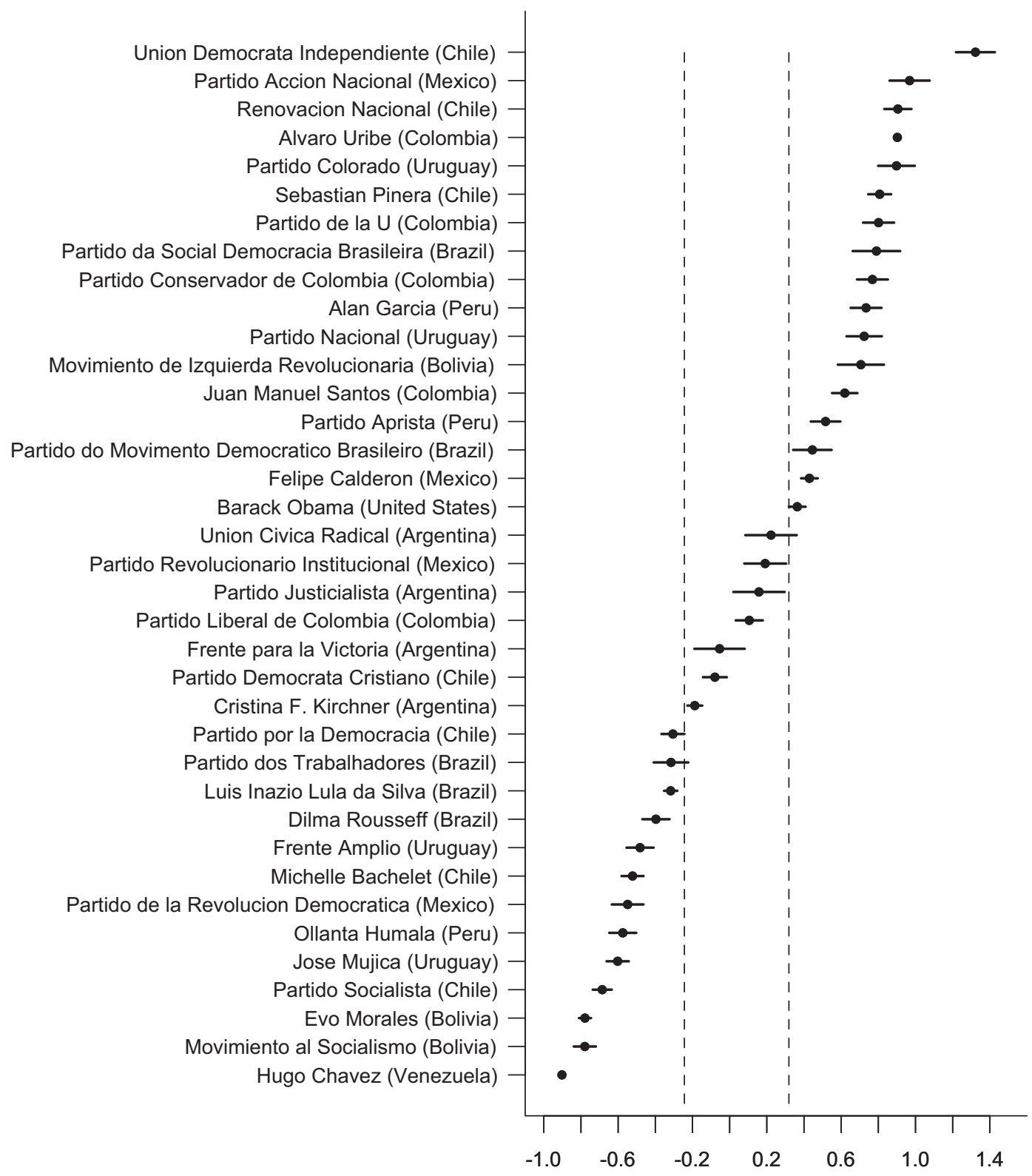

Fig. 6 Stimuli location (left to right): Point estimates and 95\% credible intervals.

of Latin American parties and politicians. Indeed, the pairwise correlations between the BAM scores, the raw (uncorrected) ideological PELA placements, and the measures constructed by Wiesehomeier and Benoit (2009) are all very large (.98, .95, and .94), indicating that they produce virtually identical stimuli configurations.

Given my implementation of the BAM method (e.g., with a relatively large sample size and diffuse priors), we should expect to obtain an equivalent arrangement of the parties and leaders using the raw scores and a frequentist approach. The similarity of these alternative stimuli configurations, however, does not suggest that the Bayesian and frequentist results are the same or that

iterations. The chains show strong evidence of convergence according to the Gelman-Rubin diagnostic and the unimodality of posterior distributions. 
they are necessarily providing comparable interpretations. The BAM scores provide a more valid measure of legislators' perceptions of parties and politicians than the countrywide means of the raw placements for a number of reasons. First, the Bayesian implementation adheres more closely than the frequentist approach to the original intuition in Aldrich and McKelvey (1977). As Armstrong et al. (2014b) note, the A-M model assumes that the stimuli occupy nearly fixed positions and the variation lies in respondents' perceptions of these locations. Bayesian scaling allows the measurement error to enter where the model suggests it should: in the respondents' distortion parameters. ${ }^{33}$ The small standard errors associated with the stimuli estimates' posterior densities suggest that the Bayesian estimation is accurately capturing this feature of the A-M model. Second, like Poole's (1998) blackbox technique, the Bayesian approach allows for the inclusion of individuals with missing responses. This property is necessary to bridge across responses from different countries (where missing data will often be present). Third, allowing for heteroskedastic errors produces better measures of uncertainty (i.e., 95\% credible intervals) for the estimated stimuli locations than a frequentist analysis of the means of the raw placements. Indeed, as the results presented in Fig. 6 indicate, the BAM scores allow one to successfully discriminate between stimuli on the basis of ideology both across as well as within countries. ${ }^{34}$

Overall, a clear pattern emerges from the configuration presented in Fig. 6: the stimuli are grouped into three distinctive clusters. The first comprises a host of left-wing leaders and parties in the region, including Hugo Chávez at its most leftist member and Chile's Party for Democracy (Partido por la Democracia) as its most moderate one. The second group is located at the center of the ideological spectrum and encompasses a variety of political actors. These include Argentine president Cristina Fernández de Kirchner to the left, Colombia's Liberal Party (Partido Liberal) in the center, and Argentina's Radical Civic Union (Unión Cívica Radical) to the right. Finally, a third cluster includes all the stimuli on the right of the political spectrum. Interestingly, US president Barack Obama, a liberal Democrat — but hardly a socialist, as some Tea Party members would assert - is the most moderate member of this group. At the far right is Chile's conservative Independent Democratic Union (Unión Demócrata Independiente) Party.

With regard to the ideological congruence of presidents and their parties, the patterns in Fig. 6 are also quite revealing. The location of most presidents tends to overlap with their parties' recovered position. This is the case with Bolivia's Evo Morales and the Movement for Socialism (Movimiento al Socialismo), Uruguay's José Mujica and the Broad Front (Frente Amplio), Brazil's Luiz Inazio Lula da Silva and the Workers Party (PT), Argentina's Cristina Kirchner and the Front for Victory (Frente Para la Victoria), and Chile's Sebastián Piñera and National Renewal (RN). Two other presidents are very close to their parties: Peru's Alan García, who is located slightly to the right of the American Popular Revolutionary Alliance (Partido Aprista Peruano, APRA), and Colombia's Juan Manuel Santos, who is located slightly to the left of the Party of the U (Partido de la U). The only exception is Mexico's Felipe Calderón, whose location is significantly different from the position of his party, the National Action Party (PAN).

The notoriously rocky relationship between Calderón and his own party further validates the findings presented in Fig. 6. In 2004, after expressing his willingness to contend as a PAN presidential hopeful, Calderón was dismissed from former Mexican president Vicente Fox's cabinet. His candidacy also earned him the opposition of Manuel Espino, the party's leader who was ostensibly backing his main opponent, Santiago Creel. Once president, Calderón's efforts continued to be hampered by the PAN. As Varela (2007) notes, at times it seemed easier for him to govern with the support of other political parties than with the support of his own party. With regard to the PAN's ideological position, Moreno (2009) documents how its shift to the right forced Calderón to adopt

\footnotetext{
${ }^{33}$ The key difference between Bayesian and frequentist statistical inference would concern the nature of the unknown distortion parameters $(\alpha$ and $\beta$ ). In the frequentist tradition, the assumption would be that these parameters are unknown but fixed. In Bayesian statistical inference, these parameters are considered to be random, possessing a probability distribution that reflects our uncertainty about their true value.

${ }^{34} \mathrm{~A}$ BAM implementation without heteroskedastic errors produces a very similar stimuli configuration but less efficient estimates. See the online Supplementary Materials for more details.
} 
more moderate positions to attract the support of both public opinion as well as other political forces with legislative representation.

\subsection{Voters and Elected Officials}

An examination of the results presented in Figs. 3 and 4 suggests that Latin American politicians possess ideological views that map on to the preference of their voters quite well. The recovered measures of voters' ideology and the placement of the stimuli, however, are not directly comparable. The PELA and CSES can be used to link the policy preferences of voters within a country to the preferences of their representatives. Recall that voters are not placing the elites as stimuli, but rather both the CSES and PELA respondents face a common set of questions. The PELA survey explicitly indicates each legislator's partisan affiliation. In the case of Module 3 of the CSES, the survey includes the following question: "Which party do you feel closest to?" I used this information, and followed the Latinobarómetro criteria mentioned above to classify both legislators and voters as government or opposition supporters. ${ }^{35}$

First of all, it is important to test whether the raw self-placements of voters and legislators are actually different. The Kolmogorov-Smirnov $D$ statistic is a particularly useful measure. It quantifies the distance between the empirical distribution functions of two samples, and its distribution is calculated under the null hypothesis that the samples are drawn from the same distribution. The results indicate that significant differences in the ideological self-placement of voters and legislators exist in Brazil, Mexico, and Peru. ${ }^{36}$

Figure 7 illustrates the voter-legislator distance for the case of Brazil. The solid (dashed) line is the empirical cumulative distribution function (ECDF) of the ideological self-placement of legislators (voters). As the graph indicates, the median legislator in the sample places himself/herself at 4.5 , significantly to the left of the country's median voter (who places himself/herself at 7). Based on this evidence, it is tempting to conclude that legislators are much more leftist than voters in Brazil. It seems more sensible, though, to consider the possibility that these two groups are interpreting the scale differently.

Using the merged PELA/CSES data set in conjunction with Aldrich and McKelvey's (1977) scaling method, it is possible to construct more accurate measures of the policy preferences of both citizens and politicians in these four countries. In Fig. 8, I present a series of kernel density estimates to compare the ideological location of voters and legislators in each country. The distribution of legislators' recovered ideological positions is represented by a black dashed line. The solid gray line indicates the distribution of voters' estimated ideological placements. Each graph also shows voters' mean estimated ideological position (solid gray vertical line), as well as a one-standarddeviation increase/decrease from that mean (gray vertical dashed line).

The estimates suggest that the views of voters and politicians are largely congruent in Brazil and Chile. In the latter country, legislators are located slightly to the right of the voting population. Yet their positions are within one standard deviation of the average voter's location. In the case of Brazil, some of the voters on the left seem to be underrepresented. And, while these voters' location exceeds a one-standard-deviation increase from the average voter's position, they are not too numerous. ${ }^{37}$ The results also indicate that legislators are more "leftists" than their voters in Mexico and Peru. The ideological drift, however, is not too severe in Mexico. Even though both legislators on the right and on the left have more "leftist" positions than their voters, their locations are for the most part within one standard deviation of the location of the average voter in the country. ${ }^{38}$

\footnotetext{
${ }^{35}$ The overall response rate of the CSES question is $63 \%$ (with a minimum of $43 \%$ in Chile and a maximum of $75 \%$ in Uruguay). With the exception of Uruguay, the sample of respondents who provided an answer is representative of the entire sample with respect to ideological locations. Therefore, I exclude this country from the analysis.

${ }^{36}$ The $D$ statistics and associated $p$-values are the following: Brazil: $D=0.4295, p$-value $=0.000$; Chile: $D=0.1303$, $p$-value $=0.110 ;$ Mexico: $D=0.5229, p$-value $=0.000 ;$ Peru: $D=0.1859, p$-value $=0.007$.

${ }^{37}$ The Kolmogorov-Smirnov $D$ statistic and associated $p$-value for Brazil are $D=0.1936(p$-value $=0.001)$, and for Chile, $D=0.1451$ ( $p$-value $=0.059)$.

${ }^{38}$ The Kolmogorov-Smirnov $D$ statistic and associated $p$-value are $D=0.3819$ ( $p$-value $\left.=0.000\right)$.
} 


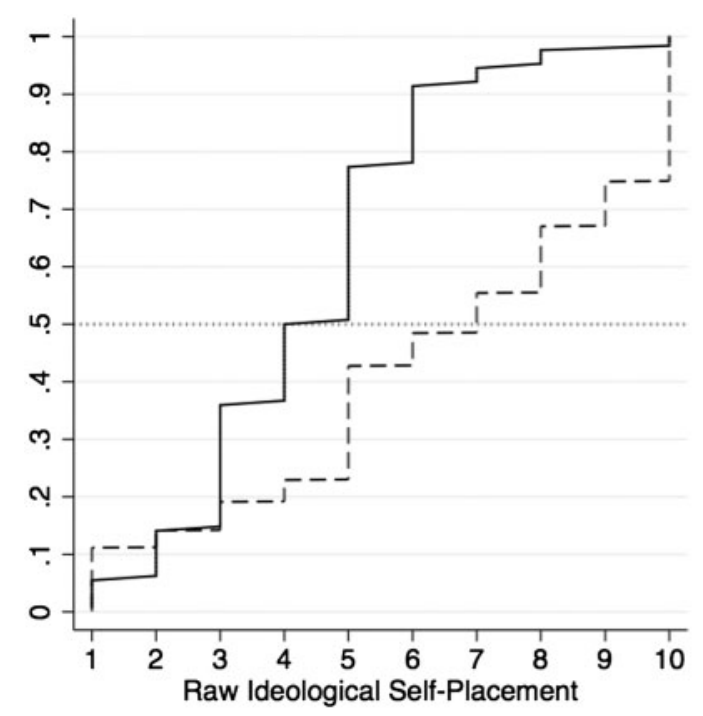

Legislators - - - - Voters

Fig. 7 ECDF, ideological self-placement of Brazilian legislators/voters.
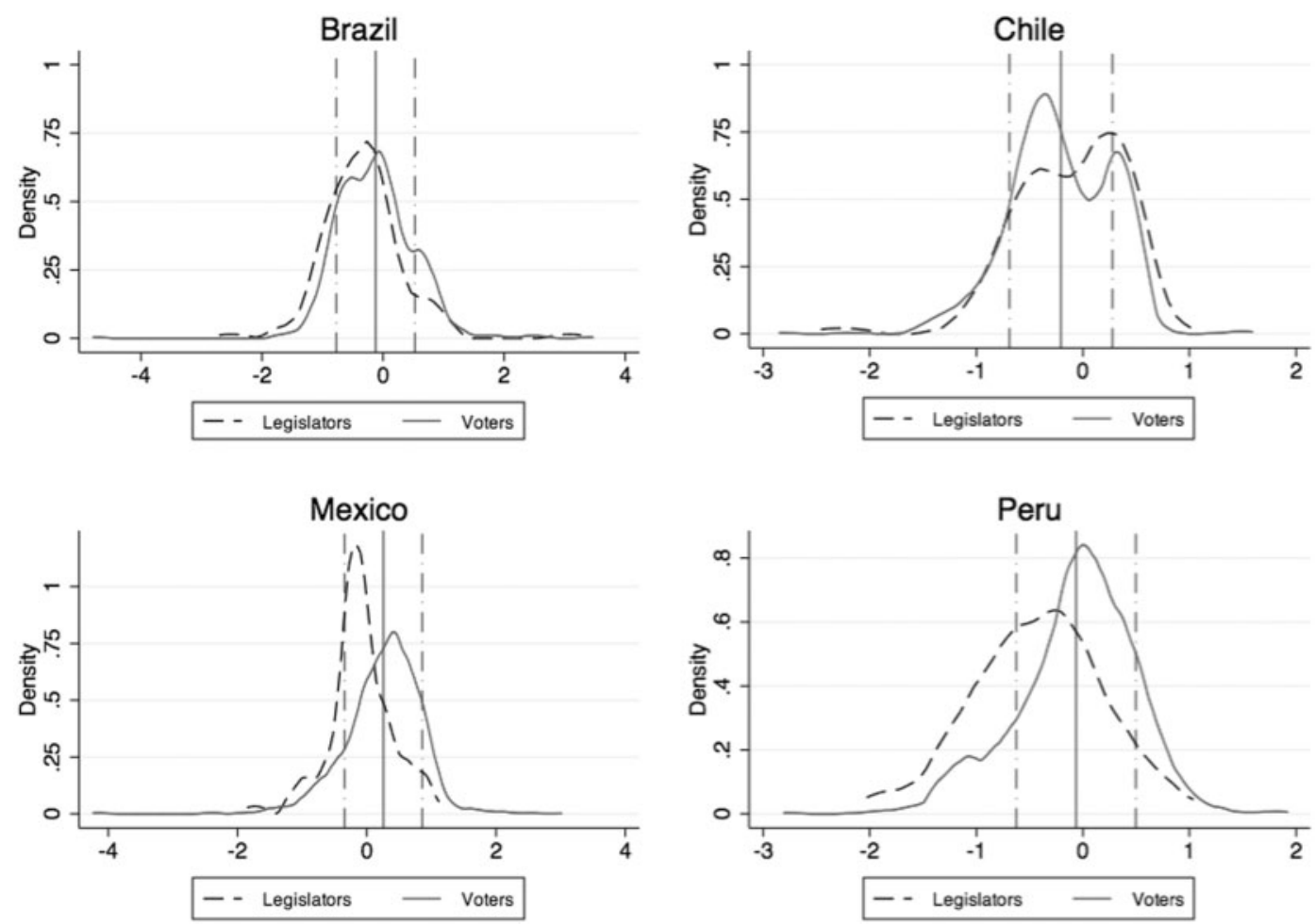

Fig. 8 Ideological location of voters and legislators.

The case of Peru deserves special attention. The findings in Fig. 8 indicate that Peruvian legislators hold consistently more leftist views than their constituents. The results square well with existing characterizations of Peru as a polity with an inchoate party system (Tanaka 1998; Jones 2010). It is beyond the scope of this article to explain why Peruvian legislators do not faithfully represent the political views of their constituents. But it is possible that the country's fragmented 
party politics and chronic governance problems underlie the rift between voters and politicians. Note that this is the only country where a victory by the left with the support of right-wing voters would be conceivable. Furthermore, both Alan García (the incumbent president when the CSES survey took place) and the American Popular Revolutionary Alliance (APRA) are located to the right of the political spectrum. The evidence presented in Fig. 8 therefore offers little support for the view that a significant disconnect between voters and politicians lies behind the success of Latin America's left at the polls.

\section{Concluding Remarks}

A long-standing methodological debate regarding how to measure and assess political representation exists. At its core lies the issue of obtaining valid estimates of ideology from disparate populations. This article makes a significant contribution of this methodological debate by tackling three DIF problems that plague statistical analyses of representation: (1) perceptual biases; (2) crosscountry comparability; and (3) disjoint samples. I highlight the benefits of using joint scaling methods and similar survey items to study representation with an examination of the ideological location of voters and politicians in Latin America.

The results demonstrate how scale perception biases lead to misleading conclusions about the relationship between ideology and voting behavior. In particular, contrary to conventional wisdom, they indicate that ideology is an important determinant of vote choice in Latin America, and that the region's elected officials are responsive to their constituents. As such, these findings have important implications regarding the link between ideology and policymaking as well as the quality of representation in Latin America.

More generally, the approach championed in this article not only provides superior measures of the policy preferences of both citizens and politicians in Latin America but can also help researchers address a whole host of questions that have previously gone unanswered. For example, they can be employed to uncover the main dimensions of conflict in each of these countries in a truly comparative manner. Also, as demonstrated by the analysis of the location of parties and leaders, the measures can also be used to assess the relative position of different political actors across national borders. Finally, the comparisons between the ideological location of voters and elected officials advanced in this article provide a valid approach to explore the quality of representation in young democracies.

Conflict of interest statement. None declared.

\section{References}

Abrajano, Marisa. 2015. Reexamining the racial gap in political knowledge. Journal of Politics 77:44-54.

Achen, Christopher H. 1977. Measuring representation: Perils of the correlation coefficient. American Journal of Political Science 21:805-15.

- 1978. Measuring representation. American Journal of Political Science 22:475-510.

Aldrich, John H., and Richard McKelvey. 1977. A method of scaling with applications to the 1968 and 1972 presidential elections. American Political Science Review 71:111-30.

Alvarez, R. Michael, and Jonathan Nagler. 2004. Party system compactness: Measurement and consequences. Political Analysis 12:46-62.

Armstrong, Dave, Ryan Bakker, Royce Carroll, Christopher Hare, Keith T. Poole, and Howard Rosenthal. 2014a. Analyzing spatial models of choice and judgment with R. Boca Raton, FL: CRC Press.

Armstrong, Dave, Ryan Bakker, Royce Carroll, Christopher Hare, and Keith T. Poole 2014b. Bayesian AldrichMcKelvey scaling. Unpublished manuscript, University of Georgia, Department of Political Science.

Arnold, Jason Ross, and David J. Samuels. 2011. Eividence from public opinion. In The resurgence of the Latin American left, eds. Steven Levitsky and Kenneth M. Roberts, 31-51. Baltimore: Johns Hopkins University Press.

Bafumi, Joseph, and Michael C. Herron. 2010. Leapfrog representation and extremism. American Political Science Review 104:519-42.

Bakker, Ryan, Seth Jolly, Jonathan Polk, and Keith Poole. 2014. The European common space. Journal of Politics 76(4):1089-1101.

Battista, James Coleman, Michael Peress, and Jesse Richman. 2013. Common-space ideal points, committee assignments, and financial interests in the state legislatures. State Politics \& Policy Quarterly 13:70-87. 
Blanco, Luisa, and Robin Grier. 2013. Explaining the rise of the left in Latin America. Latin American Research Review 48:68-90.

Booth, John A., and Patricia Bayer Richard. 2015. Latin American political culture: Public opinion and democracy. Thousand Oaks, CA: CQ Press.

Castañeda, Jorge, and Patricio Navia. 2006. Latin America's left turn. Foreign Affairs 85:28-43.

Cleary, Matthew R. 2006. Explaining the left's resurgence. Journal of Democracy 17:35-49.

Colomer, Josep M. 2005. La dimensión izquierda-derecha en América Latina. Desarrollo Económico 45:123-36.

Coppedge, Michael 2010. Data on Latin American party systems. http://www.nd.edu/mcoppedg/crd/datalaps.htm (accessed September 11, 2013).

Debs, Alexandre, and Gretchen Helmke. 2010. Inequality under Democracy: Explaining the Left Decade in Latin America. Quarterly Journal of Political Science 5:209-241.

Gerber, Elisabeth R., and Jeffrey B. Lewis. 2004. Beyond the median: Voter preferences, district heterogeneity, and political representation. Journal of Political Economy 112:1364-1382.

Golder, Matt, and Jacek Stramski. 2010. Ideological congruence and electoral institutions. American Journal of Political Science 54:90-106.

Hare, Christopher, David A. Armstrong, Ryan Bakker, Royce Carroll, and Keith T. Poole. 2014. Using Bayesian Aldrich-McKelvey scaling to study citizens' ideological preferences and perceptions. American Journal of Political Science 10. 1111/ajps.12151.

Heckman, James J. 1979. Sample selection bias as a specification error. Econometrica 47:153-62.

Huber, John D., and G. Bingham Powell. 1994. Congruence between citizens and policymakers in two visions of liberal democracy. World Politics 46:291-326.

Jessee, Stephen A. 2010. Partisan bias, political information, and spatial voting in the 2008 presidential election. Journal of Politics 72:327-40.

Jessee, Stephen A., and Neil Malhotra. 2013. Public (mis)perceptions of Supreme Court ideology: A method for directly comparing the positions of citizens and justices. Public Opinion Quarterly 77:619-34.

Jones, Mark P. 2010. Beyond the electoral connection. In How democracy works, eds. Carlos Scartascini, Ernesto Stein, and Mariano Tommasi, 19-46. Washington, DC: IDB-Harvard University Press.

Kam, Christopher. 2001. Do ideological preferences explain parliamentary behaviour? Evidence from Great Britain and Canada. Journal of Legislative Studies 7:89-126.

King, Gary, Christopher J. L. Murray, Joshua A. Salomon, and Ajay Tandon. 2004. Enhancing the validity and crosscultural comparability of survey research. American Political Science Review 97:4.

König, Thomas, Moritz Marbach, and Moritz Osnabŕ'ugge. 2013. Estimating party positions across countries and time-A dynamic latent variable model for manifesto data. Political Analysis 21:468-91.

Lax, Jeffrey, and Justin H. Phillips. 2012. The democratic deficit in the states. American Journal of Political Science 56:148-66.

Levitsky. Steven, Kenneth M. Roberts, eds. 2011. Baltimore: Johns Hopkins University Press.

Lewis, Jeffrey B., and Chris Tausanovitch 2013. Has joint scaling solved the Achen objection to Miller and Stokes? Mimeo, UCLA Department of Political Science.

Lo, James, Sven-Oliver Proksch, and Thomas Gschwend. 2014. A common left-right scale for voters and parties in Europe. Political Analysis 22(2):205-23.

Lupu, Noam 2009. Electoral bases of leftist presidents in Latin America. Unpublished manuscript, University of Wisconsin, Department of Political Science.

- 2013. Party brands and partisanship: Theory with evidence from a survey experiment in Argentina. American Journal of Political Science 57:49-64.

Malhotra, Neil, and Stephen A. Jessee. 2014. Ideological proximity and support for the Supreme Court. Political Behavior 36:917-846.

McDonald, Michael D., Silvia M. Mendes, and Ian Budge. 2004. What are elections for? Conferring the median mandate. British Journal of Political Science 34:1-26.

Miller, Warren E., and Donald E. Stokes. 1963. Constituency influence in Congress. American Political Science Review $57: 45-56$.

Moreno, Alejandro. 2009. La desición electroral. Votantes, partidos, y democracia en México. Mexico, DF: Miguel Ángel Porrua.

Murillo, María Victoria, Virginia Oliveros, and Milan Vaishnav. 2010. Electoral revolution or democratic alternation? Latin American Research Review 45:87-114.

Palfrey, Thomas R., and Keith T. Poole. 1987. The relationship between information, ideology, and voting behavior. American Journal of Political Science 31:511-30.

Poole, Keith T. 1998. Recovering a basic space from a set of issue scales. American Journal of Political Science 42:954-93.

Poole, Keith T., Howard Rosenthal, Jeffrey Lewis, James Lo, and Royce Carroll. 2013. basicspace: a package to recover a basic space from issue scales. R package version 0.07. http://CRAN.R-project.org/package=basicspace.

Powell, G. Bingham. 2004. Political representation in comparative politics. Annual Review of Political Science 7:273-96.

- 2009. The ideological congruence controversy: The impact of alternative measures, data, and time periods on the effects of election rules. Comparative Political Studies 42:1475-1497. 
Plummer, Martyn. 2003. JAGS: A Program for Analysis of Bayesian Graphical Models Using Gibbs Sampling. http://mcmc-jags.sourceforge.net/ (accessed September 11, 2014).

- 2013. rjags: Bayesian Graphical Models using MCMC. R package version 3-10. http://CRAN.R-project. org $/$ package $=$ rjags $($ accessed September 11, 2014)

Remmer, Karen L. 2012. The rise of leftist-populist governance in Latin America: The roots of electoral change. Comparative Political Studies 45:947-72.

Royston, Patrick, and Douglas Altman. 1994. Regression using fractional polynomials of continuous covariates. Applied Statistics 43(3):429-67.

Saiegh, Sebastian M. 2015. Replication data for: Using joint scaling methods to study ideology and representation: Evidence from Latin America. doi:10.7910/DVN/29342.

Seligson, Mitchell A. 2007. The rise of populism and the left in Latin America. Journal of Democracy 18:81-95.

Shapiro, Robert Y. 2011. Public opinion and American democracy. Public Opinion Quarterly 75:982-1017.

Shor, Boris. 2011. All together now: Putting Congress, state legislatures, and individuals in a common ideological space to assess representation at the macro and micro levels. Available at SSRN: http://ssrn.com/abstract=1697352.

Shor, Boris, and Jon C. Rogowski. 2010. Congressional voting by spatial reasoning. Paper presented at the Annual Meeting of the Midwest Political Science Association, Chicago, IL.

Smith, Peter H. 2012. Democracy in Latin America. New York: Oxford University Press.

Stokes, Susan C. 2001. Mandates and democracy: Neoliberalism by surprise in Latin America. New York: Cambridge University Press.

Tanaka, Martin. 1998. Los espejismos de la democracia: El colapso del sistema de partidos en el Perú, 1980-1995. Lima: IEP.

Tausanovitch, Chris, and Christopher Warshaw. 2013. Measuring constituent policy preferences in Congress, state legislatures, and cities. Journal of Politics 75:330-42.

Varela, Helena. 2007. El día que Calderón ya no quiso dormir con el enemigo: Las relaciones del presidente y el PAN. EstePaís 197:31-33.

Weyland, Kurt. 2011. The left: Destroyer or savior of the market model? In The resurgence of the Latin American left, eds. Steven Levitsky and Kenneth M. Roberts, 71-92. Baltimore: Johns Hopkins University Press.

Whitefield, Stephen. 2006. Mind the representation gap. Comparative Political Studies 39:733-58.

Wiesehomeier, Nina, and Kenneth Benoit. 2009. Presidents, parties, and policy competition. Journal of Politics 71:1435-1447.

Wiesehomeier, Nina, and David Doyle. 2012. Attitudes, ideological associations, and the left-right divide in Latin America. Journal of Politics in Latin America 4:3-33.

Wilcox, Clyde, Lee Sigelman, and Elizabeth Cook. 1989. Some like it hot: Individual differences in responses to group feeling thermometers. Public Opinion Quarterly 53:246-57.

Wilcox, Rand R., David M. Erceg-Hurn, Florence Clark, and Michael Carlson. 2014. Comparing two independent groups via the lower and upper quantiles. Journal of Statistical Computation and Simulation 84:1543-1551.

Zechmeister, Elizabeth, and Margarita Corral. 2013. Individual and contextual constraints on ideological labels in Latin America. Comparative Political Studies 46:675-701. 